\title{
A Comparison of Laparoscopic and Open Inguinal Hernia Repair in Servicemen
}

\author{
Sqn Ldr D R Andrew \\ MB, ChB, FRCS (Glasg), RAF \\ Consultant Surgeon \\ Fit Lt S B Middleton \\ $\mathrm{MB}, \mathrm{ChB}, \mathrm{RAF}$ \\ SHO Surgery \\ Wg Cdr D R Richardson \\ MB, BS, FRCSE, RAF \\ Consultant Surgeon
}

\begin{abstract}
Attributed to the Department of Surgery, Princess Alexandra's Royal Air Force Hospital, Wroughton, Swindon, Wilts SN4 0QJ
\end{abstract}

SUMMARY: In a prospective comparison of 70 servicemen undergoing inguinal hernia repair by either the Shouldice method or by laparoscopy, it was found that the laparoscopic operation took longer (mean 52.6 minutes compared to 28.4) and required a postoperative hospital stay as long as that following open operation. However the postoperative analgesia requirement was significantly less, and the patients undergoing laparoscopic herniorraphy were able to regain full fitness and to return to work earlier than those having a Shouldice repair. Despite the higher costs of the laparoscopic operation we believe that the earlier return to work makes this technique cosit. effective.

\section{Introduction}

Convalescence following inguinal hernia repair remains a significant cause of time lost from work. Two studies in 1980 and 1981 revealed that the mean time off work following herniorrhaphy was 51 and 65 days respectively $(1,2)$; however a recent report(3) suggests that the mean time may now be only 28 days. A reduced interval between surgery and the patients' return to work has obvious socio-economic effects for the working population at large, but is of greater significance within the Armed Services, where an early return to full fitness for a serviceman has direct consequences on the effectiveness of his unit.

Minimally invasive techniques of inguinal hernia repair have been developed which reduce both the recovery time and postoperative discomfort (4). We employ a laparoscopic technique of stapling a nylon mesh preperitoneally to cover the internal ring and the posterior wall of the inguinal canal. The peritoneum over the posterior wall of the inguinal canal is divided transversely and the peritoneal flaps are raised to expose the internal ring and the posterior aspect of the conjoint tendon. A 5 inch by 3 inch polypropylene mesh is inserted and stapled along its superior, medial and lateral borders to the conjoint tendon. The inferior border is not stapled because of the risk of damage to the iliac vessels. This technique has been described elsewhere(5).

In this study, 70 Servicemen undergoing inguinal hernia repair by either the laparoscopic technique or the open Shouldice method were compared for their recovery from the operation.

\section{Patients and Methods}

In the twelve months from September 1992 we haye performed 40 laparoscopic inguinal hernia repairs in $\$ 5$ Service patients ( 5 had bilateral repairs). Five of these hernial were recurrent. For the purposes of thess comparative study, a similar number of servicemento undergoing inguinal hernia repair by the Shouldice method were included. Two patients in this group had $\mathbb{Q}$ bilateral herniae and six had recurrent herniae. All $\overrightarrow{\vec{P}}$ patients were males; the mean age in the laparoscopic group was 33.5 years (range $18-64$ ) and in the Shouldice group was 38.9 years (range $19-57$ ). The parameters examined were: operation time, postoperative hospital

Table 1

Comparison of Open and Laparoscopic Inguinal Hernia Repair

\begin{tabular}{|c|c|c|}
\hline $\begin{array}{l}\text { Operating Time } \\
\text { (minutes) }\end{array}$ & $\begin{array}{c}\text { Open } \\
28.4\end{array}$ & $\underset{52.6}{\text { Laparoscopic }}$ \\
\hline $\begin{array}{l}\text { Hospital Stay } \\
\text { (days) }\end{array}$ & 1.2 & 1.3 \\
\hline $\begin{array}{l}\text { Postoperative } \\
\text { Analgesia }\end{array}$ & ++ & + \\
\hline $\begin{array}{l}\text { Return to work } \\
\text { (weeks) }\end{array}$ & 4.5 & 2.7 \\
\hline $\begin{array}{l}\text { Return to full fitness } \\
\text { (weeks) }\end{array}$ & 6.3 & 3.5 \\
\hline Complications & + & + \\
\hline Recurrence & $1 / 35$ & $0 / 35$ \\
\hline Cost $(\mathfrak{E})$ & 11 & 326 \\
\hline
\end{tabular}


stay, time off work and time for recovery to full fitness, and postoperative analgesia requirement. In addition, we monitored the incidences of complications and early recurrence. The patients were reviewed in the outpatients department, and their recovery assessed using a standardised questionnaire. One patient in the laparoscopic group and two in the Shouldice group were lost to follow-up, therefore for some parameters only the information from 34 laparoscopic repairs and from 33 Shouldice repairs was obtainable.

\section{Results (Table 1)}

a) Operation Time.

The mean time to perform a Shouldice procedure was 28.4 minutes. The operation times for the bilateral repairs were similar as in both cases the two sides were performed concurrently. As experience increased, there was an obvious reduction in the time required to perform a laparoscopic herniorrhaphy. The overall mean time was 52.6 minutes, but that for the first six procedures was 66.5 minutes compared to 39.2 minutes for the last six in this series. Bilateral repairs cannot be performed concurrently laparoscopically, and the mean time for the five bilateral repairs was 75.6 minutes.

\section{(b) Hospital Stay.}

In the laparoscopic group, 26 patients $(74 \%)$ were discharged on the first postoperative day: this included four patients who had had bilateral repairs; 7 patients $(20 \%)$ - including the fifth patient, undergoing bilateral herniorrhaphy - went home on the second day and the remaining two patients $(6 \%)$ required three days in hospital. In the Shouldice group, 28 patients $(80 \%)$ went home on day $1,5(14 \%)$ on day 2 , and $2(6 \%)$ on day 3 . Thus, there was no significant difference between the two groups with regard to postoperative hospital stay.

\section{(c) Postoperative Analgesia.}

Our patients required less analgesics after laparoscopic surgery than after open surgery. Thirty-three patients $(94 \%)$ - required narcotic analgesia in the 24 hours following Shouldice repair compared to 13 patients (37\%) after laparoscopic surgery. Similarly, the consumption of Paracodol (Fisons) (paracetamol/codeine phosphate) by the patients in the Shouldice group was more than twice that in the laparoscopic group, with a mean requirement of 5.5 tablets (range $0-24$ ), compared with 2.4 tablets (range $0-10$ ). Only four patients $(11 \%)$ required no analgesics following Shouldice repair, compared with 8 patients (23\%) after laparoscopic surgery.

\section{(d) Return to work and to full fitness.}

There were two patients in the laparoscopic group who developed complications which significantly delayed their recovery. There was no similar instance in the Shouldice group. For the remaining patients the results were as follows: the mean postoperative period off work was 4.5 weeks in the Shouldice group and 2.7 weeks in the laparoscopic group. The mean recovery time to full fitness was 6.3 weeks and 3.5 weeks respectively. Thus, the patients undergoing inguinal herniorrhaphy appeared to make more rapid recovery and were able to return to work several weeks earlier if the operation was performed laparoscopically rather than by open surgery.

\section{(e) Recurrence Rate.}

One patient developed a recurrence of his hernia within six months of a Shouldice operation. This was corrected by laparoscopic repair. (It is of note that he was able to return to work three weeks after his laparoscopic herniorrhaphy, compared to eight weeks after the Shouldice procedure.) There have been no instances of recurrence in the laparoscopic group to date.

\section{Table 2}

Complication Rates following Open and Laparoscopic Inguinal Hernia Repair

\begin{tabular}{lcc}
\hline Wound bruising & Open & Laparoscopic \\
Wound infection & 1 & - \\
Pubic tubercle pain & 4 & - \\
Nerve damage & 2 & 3 \\
Extraperitoneal & - & 2 \\
insufflation & - & 3 \\
$\begin{array}{l}\text { Damage to cord } \\
\text { structures }\end{array}$ & - & \\
UTI & - & 1
\end{tabular}

(f) Complications (Table 2)

In the Shouldice group three patients developed superficial wound infections and one patient complaine娄 $\Phi$ of bruising around the wound. At six weeks post $\vec{\theta}$ operation, four patients had pubic tubercle tenderness ang two patients had paraesthesia in the distribution of the ilio-inguinal nerve. In the laparoscopic group, one patieff developed a urinary tract infection, presumably as a resu熵 of the bladder catheterisation which is a preliminary part of the laparoscopic procedure. In two procedures the Veress needle was inserted incorrectly, resulting in extraperitoneal insufflation. One patient was noted to have pubic tubercle tenderness. Damage to spermatic cord structures occurred in three patients: in one case the vas was partially divided during scissor dissection, and two patients had cord haematomata - one of which took some four months to settle. Three patients were noted to have meralgia paraesthetica which only became apparent fortyeight hours post-operation. In two cases the thigh pain was mild and resolved spontaneously within six weeks, however the third patient had bilateral thigh pain of considerable intensity, and this seemed to trigger symptoms of a neurosis, requiring his referral for psychiatric help. We believe that the meralgia is caused by damage during dissection to the lateral cutaneous nerve as it passes through the lateral end of the inguinal ligament.

\section{Costs}

The costs of the five sutures for a Shouldice repair, a scalpel blade and a wound dressing amount to $£ 11.36$. For $ᄋ$ the laparoscopic procedure, reusable laparoscopic $N$ instruments are employed wherever possible, but the N laparoscopic ports, the disposable staple gun, and the polypropylene mesh, together with the urinary catheter, 
scalpel blade and wound dressings amount to $£ 325.66$. Re-usable ports and a stapler have been ordered which will reduce this cost to $£ 137.66$.

\section{Discussion}

From our early experience, laparoscopic repair of inguinal herniae takes longer and involves considerably more expense in operating instruments and material than the Shouldice technique and, like the open procedure, is not without potential complications. However we have found that with increasing experience, the operating time can be brought down to a level comparable to that of the open method, and that the risk of complications can be reduced.

Recently, Devlin(6) stated that recurrence rates under $1 \%$ should be the norm, but several studies $(7,8)$ in the United States have shown that the recurrence rate of the Shouldice procedure, even in specialist hernia centres, is still $8-10 \%$. Our series is not large enough to give an accurate prediction of the recurrence rate following laparoscopic repair, but the lack of any instances of recurrence at up to twelve months post-operation is encouraging.

Unlike the laparoscopic technique of cholecystectomy, laparoscopic hernia repair does not allow the patient to go home any sooner, as patients are discharged within 24 hours of hernia repair regardless of approach. However, the lower analgesia requirement following laparoscopic repair indicates that this method produces less pain than the Shouldice procedure. We believe that the principal advantage of the laparoscopic technique is the shorter recovery period and return to work. Our figure of 4.5 weeks off work following Shouldice herniorrhaphy corresponds closely with that reported by Rider and his colleagues(3): our patients undergoing laparoscopic herniorrhaphy were able to return to work considerably sooner. Despite the high cost in disposable instruments we believe the earlier return to work makes the procedure cost-effective, but within the context of the Armed Forces it has a more direct effect on the fitness of servicement undergoing hernia surgery.

\section{REFERENCES}

1. SEMmence A, KYnCH J. Hernia repair and time off work in Oxford. J R Coll Gen Pract 1980; 30: 90-6.

2. Bourke J B, LEAR P A, TAYLOR M. The effect of early return to work after elective repair of inguinal hernia: clinical and financial consequences at one year and three years. Lancet 1981; ii: 623-5.

3. Rider M A, BAKer D M, Locker A, FAwCETt A N. Return to work after inguinal hernia repair. Br J Surg 1993; 80: 745-6.

4. DiON Y M, Morin J. Laparoscopic inguinal herniorrhaphy. Can J Surg 1992; 35(2): 209-12.

5. Salerno G M, Fitzgibbons R J, Filipi C J. Laparo- $\overrightarrow{+}$ scopic Hernia Repair. In: Zucker ed, Surgical ồ Laparoscopy, St Louis: Quality Medical Publishing ơ Inc. 1991: 284-93.

6. DeVLin H B. Groin hernias. Surgery 1993; 11(5몽 385-96.

7. Conceptualisation and measurement of physiologac health for adults. Santa Monica, CA: Rand, 1983: 120.

8. Martin R E, Max C C. Primary inguinal herngia + repair with prosthetic mesh. HospiMedica 198速 1(3): 1-2. 